\title{
MULHERES NA "FORNADJA". TECENDO CAMINHOS (IM)POSSÍVEIS PARA A EMIGRAÇÃO
}

\author{
Carla Santos de Carvalho \\ Universidade de Cabo Verde, Praia, Cabo Verde
}

Resumo: A emigração transnacional masculina é um fenómeno antigo em Cabo Verde. Nos anos mais recentes observam-se, nas pequenas comunidades rurais, mudanças em relação às atividades e à posição social das mulheres remanescentes no que toca à ocupação dos espaços tradicionalmente masculinos. As mulheres ocupam este espaço como um meio para prover o respectivo agregado familiar, mas também é uma estratégia para alcançarem os caminhos da emigração. O presente artigo procura analisar as mudanças sociais e familiares nas relações de género que ocorrem simultaneamente nos espaços de produção e nos espaços domésticos da Ribeira de Principal, ilha de Santiago, Cabo Verde, no âmbito das estratégias de emigração para a Europa.

Palavras-chave: "Fornadja"; Género; Emigração; Meio rural; Cabo Verde.

\section{Introdução}

Nas visitas realizadas à comunidade rural de Ribeira de Principal percebemos que em vários agregados familiares havia membros, principalmente do sexo masculino, que estavam emigrados. Essa emigração acontecia essencialmente para os países da Europa. Convém realçar que a emigração não é um fenómeno novo nas ilhas de Cabo Verde. Entretanto, constatamos que novo é o espaço que as mulheres passaram a ocupar com a saída dos homens da comunidade para a emigração. Ou seja, encontramos mulheres a trabalhar num espaço tradicionalmente tido como masculino, as "fornadjas"' .

Esse facto é novo uma vez que as "fornadjas", no país e na comunidade, constituiu um espaço de produção ocupado pelos homens para a produção do grogue (aguardente)

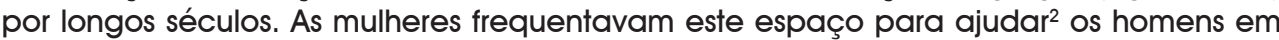

\footnotetext{
(c) (i) Esta obra está sob licença Creative Commons.

Espaço de produção do grogue (aguardente) constituído por alambiques (equipamentos, feitos de cobre para a destilação do grogue) e "trapiches" (equipamentos para a moagem da cana sacarina).

${ }^{2}$ Refere-se ao trabalho como um processo de inserção no circuito de produção, comercialização e decisão dos bens produzidos.
} 
tarefas como o transporte da água e lenha, levar refeições aos maridos/companheiros e a transportar o grogue para casa. Mas, agora, a mulher ocupa o espaço da "fornadja" para a produção e comercialização do grogue. A produção do grogue serve para o sustento do agregado familiar, mas também serve para preparar os caminhos da emigração.

Nesse sentido, propomos discutir o papel e a posição das mulheres no espaço de produção da fornadja, como uma nova prática de actividade remunerada, mas igualmente como uma estratégia para adquirir os meios para a emigração. Propomos uma linha explicativa de que a saída masculina do agregado familiar e da comunidade permite uma nova configuração sócio-familiar, em que as relações de género vão mudando, emergindo novas identidades sociais e, com elas, criando novas possibilidades para uma emigração feminina autónoma.

Este estudo foi realizado em Ribeira Principal, uma comunidade rural na ilha de Santiago, Cabo Verde, África, enquadrado na pesquisa de campo para a dissertação de mestrado. Caracteriza-se, basicamente, por ser uma pesquisa qualitativa com recurso à etnogra-fia. A pesquisa qualitativa, em termos metodológicos, é uma abordagem que busca descrever e analisar a cultura e o comportamento humano do ponto de vista dos pesquisados (Pedro SILVA, 2003). No nosso caso, a realização da pesquisa qualitativa é pertinente porque dela vão emergir vivências que nos possibilitará compreender o fenómeno em questão. $O$ método etnográfico usado foi pertinente, porque a pesquisa não se destinava a ser representativa, impor generalização ou quantificar dados, mas compreender o comportamento das pessoas.

No contexto etnográfico, o recurso à entrevista deve-se ao facto de a mesma oferecer a possibilidade do informante alcançar a liberdade e a espontaneidade necessárias, enriquecendo a investigação (Robert G. BURGESS, 2001). A entrevista semiestruturada confere uma flexibilidade importante para o processo de recolha de dados, porque permite que as entrevistas não se limitem a perguntas pré-estabelecidas (Rodolphe GHIGLIONE; Benjamin MATALON, 2001; Tim MAY, 2004). Foram realizadas dezessete entrevistas com informanteschave, sendo doze mulheres e cinco homens; a maior parte delas está ligada à produção de grogue.

\section{O processo migratório em Cabo Verde}

Cabo Verde é um arquipélago, constituído por dez ilhas, situado no oeste africano com cerca de meio milhão de habitantes, dos quais $50,5 \%$ são do sexo feminino e $49,5 \%$ são do sexo masculino (Instituto Nacional de Estatística, 2010). Estima-se que, além dessa população de cabo-verdianos, estejam residindo em outros países, tais como Estados Unidos, França, Holanda, Senegal, São Tomé e Príncipe etc., cerca de meio milhão de cabo-verdianos emigrados ou descendentes de segunda e terceira geração. Esse fenómeno faz parte da vida socioeconómica e cultural de Cabo Verde, desde finais do século XIX, e esteve por muito tempo associado a problemas socioambientais como as constantes secas, fraca produtividade e escassez alimentar.

O arquipélago situa-se na zona saheliana que se caracteriza por um contexto climático pouco favorável à prática da agricultura, com um ecossistema extremamente frágil; os recursos naturais são reduzidos e, segundo o Recenseamento Geral da Agricultura (Ministério do Ambiente e Agricultura, 2004), as terras cultiváveis são escassas, totalizando um total de $10 \%$ da superfície do país. A população cabo-verdiana conheceu, em vários momentos da sua história, situações de pobreza extrema e, até finais da década de 1950, tiveram lugar períodos de fomes, secas e mortandades (António CARREIRA, 1972). Esse contexto tem sido explicado como o impulsionador do processo migratório. Os estudos sobre o fenómeno, geralmente, 
explicam que os fatores acima mencionados estão na base desse processo migratório (AHN, 1998; Cláudio FURTADO, 1997; Carlos Ferreira COUTO, 2001; Marzia GRASSI, 2007).

Essa visão explicativa do processo migratório em Cabo Verde pode ser enquadrada nos modelos de atração-repulsão, iniciado por Ravestein no final do século XIX e retomado por vários autores (Maria Beatriz ROCHA-TRINDADE, 1995). Tal abordagem pressupõe que, em ordem a maximizar as vantagens e a reduzir o desconforto, os indivíduos são conduzidos a efetuar escolhas racionais em função de determinadas "pressões". Assim, os fatores de repulsão e atração, "empurram" os indivíduos do seu local de origem, "atraindo-os" para outros locais. Os fatores de repulsão considerados são, fundamentalmente, de ordem económica e incluem: escassez de terras, desemprego, baixos salários, seca, fome, explosão demográfica. Os fatores de atração constituem alternativas aliciantes aos de repulsão, acrescentando-Ihes as vantagens, por exemplo, da vida urbana em contraposição à suposta estagnação vivida nas zonas rurais (ROCHA-TRINDADE, 1995).

Segundo Elisa Andrade (1995 apud GRASSI, 2007, p. 27-28) numa perspectiva temporal pode-se distinguir duas correntes de emigração, uma antiga (num quadro de dominação colonial com destino em África - Guiné Bissau, Senegal - e no quadro da pesca da baleia para os Estados Unidos) e outra moderna (durante o século XX no quadro dos contratos de trabalho para São Tomé e Príncipe e para a Europa). Podemos inferir que essas duas grandes vagas migratórias impulsionaram uma terceira, especialmente para a Europa, a partir da década de 1970, aumentando o fluxo com a independência a partir de 1975. E é a partir dessa terceira vaga que a presença feminina começa a intensificar-se no contexto migratório cabo-verdiano. Até aqui, e durante muito tempo, os homens dominaram a emigração em Cabo Verde. Entretanto, a partir desse período, o movimento migratório de cabo-verdianos pelo mundo conhece uma crescente feminização (GRASSI, 2007). É importante realçar, no entanto, que com a exceção da emigração para São Tomé e Príncipe, onde as mulheres tiveram uma participação massiva, a emigração feminina - principalmente a autónoma e independente - tem sido um novo conceito para a sociedade cabo-verdiana nas últimas três décadas (Martina GIUFFRÈ, 2007).

Várias pesquisas (GRASSI, 2007; Andréa de Souza LOBO, 2007; GIUFFRÈ, 2007) vêm demonstrando que as mulheres vêm emigrando, tanto num contexto de reagrupamento familiar, mas também, e principalmente nas últimas décadas, num processo independente em que as mulheres desempenham um papel autónomo nos processos migratórios. $O$ processo migratório continua fortemente a dominar as vontades dos cabo-verdianos; no entanto, a última década tem revelado um fenómeno inverso - a imigração. Cabo Verde era conhecido como um país de emigração, mas hoje é também conhecido como um país de imigração. É possível identificar três tipos: em primeiro lugar, imigrantes do continente, especificamente da Costa Oeste Africana, que chegam para escapar da guerra e da pobreza, mas com o objetivo de alcançar os países desenvolvidos; em segundo, imigrantes de países em desenvolvimento que vêm trabalhar nos negócios e empregos bem remunerados, muitas vezes em organizações internacionais. Em terceiro lugar estão os imigrantes chineses que vêm, principalmente, por razões comerciais.

\section{A emigração masculina na comunidade de Ribeira de Principal}

O processo migratório em Ribeira de Principal iniciou pouco antes da independência do país. Segundo os informantes, no início da década de 1970, as autoridades portuguesas autorizaram a entrada em Portugal dos cidadãos das suas colónias. Um grande número de homens da comunidade emigrou para Portugal. Os candidatos à emigração faziam 
empréstimos aos familiares e à vizinhança para custear a viagem. E, posteriormente, mandavam saldar a dívida.

A emigração na comunidade de Ribeira de Principal constitui uma estratégia dos agregados familiares, que estava frequentemente articulada às redes sociais, de solidariedade, de amizade ou vizinhança. Mas, também, a emigração constitui uma estratégia individual, pois os fatores psicológicos e individuais são importantes para determinar as motivações no processo migratório. As condições estruturais são elementos importantes que influenciam e condicionam a motivação para emigrar e, outrossim, é relevante considerar que a motivação para emigrar é gerada pela liberdade individual dos sujeitos (agency). Charles Tilly (1990) defende igualmente que a migração não pode ser explicada apenas pelos fatores de atração e repulsão que fazem as pessoas migrarem devido aos diferenciais de oferta de trabalho.

A saída do homem na comunidade, através da emigração, originou escassez da força de trabalho no processo produtivo. Essa situação levou as mulheres a ocuparem o espaço deixado vago com a saída dos homens, substituindo a força de trabalho masculina na agricultura, na horta e na "fornadja" (Carla Santos de Carvalho CARDOSO, 2009). A entrada da mulher em substituição do homem nos trabalhos agrícolas pode ser vista como um processo de continuidade, visto que já trabalhava, também, nesse espaço. Entretanto, a sua substituição deu-se em nível "político", isto é, na tomada de decisões. Aqui, a mulher decide sobre o processo produtivo - o que não acontecia quando o marido estava presente.

Constata-se, na comunidade, uma vontade enorme de emigrar e, inclusive, muitos dizem que estão a "preparar" para seguir este caminho. Verifica-se que as representações sociais projetadas sobre o emigrante, com base nas suas próprias condições de vida, criam marcas psicológicas que definem as estratégias individuais dos candidatos a emigrantes. Assim, a construção social de um imaginário "emigrante" cheio de oportunidades influencia a decisão individual - baseada em condições socioeconómicas desfavoráveis da comunidade - em seguir o caminho da emigração. Mas, na prática e, principalmente, nos primeiros dez anos, a situação do emigrante não é favorável económica ou socialmente. Devido a essa situação, os membros dos agregados familiares que ficaram, afirmam que têm de trabalhar. Porque nem sempre os familiares emigrados possuem condições para contribuir plenamente com as despesas quotidianas. Os informantes confirmam que, muitas vezes, a emigração, nos primeiros tempos, não traz tantos benefícios como se imagina e se verbaliza.

Com a emigração masculina, as mulheres/companheiras desses emigrantes foram trabalhar nas "fornadjas" por terem sentido a necessidade de contribuir para a provisão do agregado familiar, visto que esse espaço de produção é remunerado. Obviamente essa situação aconteceu porque o homem considerado o provedor da unidade familiar nem sempre possuía, no estrangeiro, condições para contribuir regularmente para a manutenção socioeconómica do agregado familiar - muitas vezes, em decorrência de sua condição de ilegalidade no país de acolhimento, o emigrante vivia numa condição de subemprego ou de desemprego. Essa situação espelha a situação de vulnerabilidade que os maridos/ companheiros estão expostos, assim como o seu próprio agregado familiar, tanto um como outro passam por condições de precariedade. Isso desencadeou a construção de novas estratégias, principalmente, pelas mulheres nessa comunidade rural, ou seja, o surgimento das "fornadjeras" externas (a emigração, as dificuldades e a precariedade socioeconómica).

${ }^{3}$ Mulheres que produzem grogue (aguardente). 
Assim, as mulheres começaram a trabalhar na "fornadja" porque é um espaço que conhecem relativamente bem, pois cresceram a frequentar a "fornadja" com o pai e, posteriormente, com o marido. Antes disso, as mulheres tinham um papel secundário no espaço da produção da "fornadja" como ajudantes de seus respectivos maridos/ companheiros.

Num primeiro momento, verificamos que paulatinamente algumas mulheres chefes dos agregados familiares - viúvas e solteiras - começaram a trabalhar na "fornadja" para garantir a provisão dos respectivos agregados. Num segundo momento, verificamos que um aumento da presença feminina nas "fornadjas" independente do estado civil e da condição socioeconómica (CARDOSO, 2009). Essa entrada da mulher e, em seguida, do aumento da sua participação na "fornadja" deve-se, por um lado, à saída masculina da comunidade no processo migratório e, por outro, foi facilitada porque durante a infância/juventude as mulheres participavam desse espaço, embora desempenhando um papel de ajudante.

\section{"Fornadja": uma ponte no processo migratório}

A maioria dos membros do agregado familiar, com exceção dos mais velhos, almeja o caminho da emigração. Em todas as casas da Ribeira de Principal encontra-se pelo menos um membro do agregado familiar emigrado. O caminho da emigração é muito desejado. A população local, particularmente as "fornadjeras" e os "fornadjeros", diz que se tivesse outras alternativas não trabalhava nas "fornadjas", mas emigrava. Pode-se observar que os agregados familiares não se confinam às unidades domésticas ${ }^{4}$, pois verifica-se a existência de uma elasticidade entre os agregados familiares que perpassam as unidades domésticas, ou seja, as relações de parentesco, advindas de várias gerações, são importantes no apoio à emigração. A trajetória dos agregados familiares no espaço da "fornadja" é importante no processo migratório para o estrangeiro. Nesse sentido, a reprodução das unidades domésticas depende, bastante, da dinâmica existente nos agregados familiares.

A "fornadja" é um dos espaços mais significativos de produção em Ribeira de Principal e permite granjear condições financeiras e construir redes para a emigração. $O$ trabalho na "fornadja" permite gerar meios de vida para a provisão dos agregados familiares e constitui um processo de diversificação dos meios de vida no espaço rural em que as famílias rurais constroem estratégias para enfrentar os "contextos de vulnerabilidade" a partir da realização de um conjunto de atividades (Frank ELLIS, 2000). A produção do grogue é uma atividade que a maioria dos agregados familiares recorrem porque há lucro, principalmente, se as redes de produção e comercialização estiverem bem organizadas.

A emigração constitui uma estratégia muito recorrida na comunidade. Entre o ano de 1995 a 2000, segundo meus informantes, um expressivo número de pessoas emigrou. A emigração dos homens e, mais tarde de outros membros do agregado familiar, entre os quais as respectivas mulheres, resulta de um processo de negociação, organizada em estratégias, sustentada por laços e redes de solidariedade e reciprocidade, construído e reconstruído no grupo doméstico e na comunidade. Assim, as redes sociais tornam-se um recurso importante para a emigração e, consequentemente, para a integração do indivíduo no país de acolhimento (Gláucia de Oliveira ASSIS, 2007; GRASSI, 2007).

Com a emigração masculina, cai por terra toda a ideia do homem provedor do agregado familiar - pois, principalmente nos primeiros anos da emigração, fica patente a situação de precariedade dos emigrantes. Assim, coube/cabe à mulher apoiar e prover o

$\overline{{ }^{4}}$ Refiro-me às pessoas com laços consanguíneos ou de afinidade partilhando a mesma casa. 
grupo - sobressaindo e revelando assim o trabalho "oculto" das mulheres. Com a ausência masculina, passa a ser, também, a pessoa de referência no grupo (isso não quer dizer que a mulher ocupou/ocupa inteiramente o lugar do homem e que ele perdeu/perde a sua posição na família).

A emigração masculina, em Ribeira de Principal, reforça o papel das mulheres na manutenção da identidade camponesa. As mulheres se tornam o principal elo entre o agregado familiar e o campo ou "fornadja", enquanto patrimónios e espaços de produção. São as mulheres que, na ausência dos maridos, passam a realizar as tarefas no espaço de produção e do consumo. Essa dinâmica só é possível porque há uma renegociação, ainda que provisória, de papéis e uma redefinição de espaços de trabalho.

Todavia, a emigração permitiu, de certa forma, uma fluidez nas relações de poder no agregado familiar uma vez que as mulheres passam a ter maiores iniciativas e tomadas de decisões, mesmo que, por vezes, sejam predominantemente relacionadas ao seu espaço de pertença e influência. Da mesma forma, não se redefine totalmente a figura do pai provedor, pois os homens nunca estão completamente ausentes. A autoridade, o poder e a honra paterna continuam sempre representados por meio de símbolos e da construção da ideia de pai.

Os emigrantes chegados ao país de acolhimento, principalmente nos primeiros anos, trabalham com o objetivo de prover e/ou ajudar a prover o agregado familiar ao qual pertencem. Os recursos enviados são utilizados em duas frentes: a primeira no processo do aumento do capital social e económico dos agregados familiares adquirindo propriedades, meios de transportes, abertura de pequenas mercearias e no início e/ou reforço na produção na "fornadja". A segunda frente é direcionada na tentativa e no empenho em apoiar os familiares a emigrarem - enviando documentação, dinheiro e contribuindo para a rede social que apoie esse processo.

A emigração masculina permitiu a reconfiguração do espaço social público e familiar, particularmente, as relações de poder e de género. Esse fenómeno contribuiu para redefinir a posição da mulher no processo de produção e influenciou novas estratégias de reprodução da unidade doméstica. As transformações incidem, principalmente, na maneira como é visto o papel de cada um desses sujeitos nas relações que se estabelecem dentro do agregado familiar, no espaço da produção e na própria construção simbólica dos sujeitos sociais de Ribeira de Principal.

\section{Novos caminhos: emigração feminina}

A emigração feminina é um fenómeno que tem aumentado na última década na comunidade, principalmente, junto às mulheres solteiras. Elas investem um esforço pessoal na emigração. E o trabalho na "fornadja", por essas mulheres, é encarado como um investimento que permitirá o acesso à emigração, uma vez que a renda alcançada permite isso. As mulheres que trabalham na "fornadja" estabelecem redes sociais com o objetivo de conseguir um visto de entrada na Europa. Essas redes sociais, associadas à realização de diversas atividades geradoras de rendimento, permitem com que realizem o processo emigratório rumo à Europa. Essa situação, segundo Giuffrè (2007), representa um novo papel autónomo desempenhado pelas mulheres nesse processo, o que em certos momentos, para o caso estudado, permite falar de "emigração feminina independente".

Geralmente, as mulheres emigrantes quando chegam aos países de acolhimento inserem-se no setor dos serviços domésticos e utilizam as redes sociais informais - os chamados enclaves étnicos de imigrantes (ASSIS, 2007) - para obterem um trabalho, geralmente, como empregadas domésticas ou empregadas de limpeza. Esse circuito também inclui-se no 
chamado redes sociais de apoio à emigração, particularmente à emigração feminina.

Tal fenómeno não é novo, muito embora tem-se verificado um aumento da participação das mulheres nos fluxos migratórios internacionais (ASSIS, 2007). Como referimos anteriormente, a emigração feminina é uma novidade em Cabo Verde, particularmente nas últimas três décadas.

Em Ribeira de Principal, os homens iniciaram o processo migratório e as mulheres fizeram o mesmo, posteriormente, no decurso da reunificação familiar. Os homens levam uma média de três a cinco anos para concluírem a legalização, dependendo do país. Depois disso, procuram mecanismos e estabelecem as redes sociais para a emigração das esposas/companheiras e do/as filho/as. Atualmente, para as mulheres casadas esse processo continua. Para as mulheres solteiras - ao contrário das mulheres casadas ou vivendo em união de facto em que essa rede é constituída juntamente com o marido/ companheiro -, esse processo é efetuado a partir da construção de suas próprias redes e por seus próprios meios, ou seja, trabalham fazendo poupanças e com o apoio de familiares ou pessoas próximas conseguem um visto de entrada para a Europa.

O fato de as mulheres passarem a trabalhar nas "fornadjas" contribuiu para a "potencialização" da posição social das mesmas, tornando-se agentes da sua própria transformação. A "potencialização" representa a expansão da liberdade de escolha e de atuação, bem como o aumento da capacidade de agir dos sujeitos sobre os recursos e decisões que afetam suas vidas (Magdalena LEÓN, 2001). Assim, as atividades que as mulheres forjam e edificam no seu quotidiano significam, na realidade, estratégias de "potencialização" que, por sua vez, permitem a transformação do contexto social e levam a construção de novos imaginários sociais.

As "fornadjeras" de Ribeira de Principal possuem no agregado familiar, assim como na própria comunidade, um poder de decisão e de transpor barreiras vedadas às outras mulheres que não exercem nenhuma atividade remunerada. Isso porque a venda do grogue gera um aumento e diversificação da fonte de renda para as mulheres o que implica mais poder para elas. Portanto, ao analisar o caso deste estudo, pode-se deduzir aqui uma agência de projetos que, segundo Sherry B. Ortner (2007), as mulheres estão promovendo suas próprias intenções, culturalmente constituídas. Assim, o trabalho da mulher na "fornadja" e toda a sua resistência para trabalhar e/ou continuar a trabalhar nesse espaço constitui, também, uma forma de "agência de poder".

As mulheres reelaboram suas estratégias dentro das relações familiares, criam e recriam cotidianamente suas ações a partir das necessidades objetivas e imediatas. Nesse sentido, as necessidades para prover o agregado familiar orientaram as novas estratégias de reprodução social, o que significou uma rearticulação das relações de género e, consequentemente, mudanças nas relações de poder no agregado familiar, tornando-se mais democrática, sem, contudo, romper com as representações ideológicas de género (CARDOSO, 2009).

O poder adquirido pelas mulheres "fornadjeras" transparece no papel exercido por elas mesmas nas mudanças substanciais ocorridas no espaço público com a sua inserção no mundo da produção, tendo status de participante nesse espaço e na comunidade de um modo geral, nas relações entre os sexos, nas modificações no agregado familiar, na transformação dos costumes ligados ao trabalho no espaço privado e público. Por isso, é legítimo afirmar que os papéis de género estão a mudar na Ribeira de Principal assim como em Cabo Verde (Isabel P. B. Fêo RODRIGUES, 2007). 


\section{Conclusão}

Através da realização desta etnografia, mostramos que na comunidade de Ribeira de Principal a saída dos homens no processo migratório contribuiu para a entrada feminina na "fornadja" - um espaço público de produção remunerado.

As mulheres inseriram-se no espaço de produção da "fornadja", num primeiro momento, para apoiar a provisão dos agregados familiares; num segundo momento, foi uma forma de afirmação de suas próprias identidades nesse espaço como sujeitos políticos no espaço público. Presentemente, a mulher utiliza esse espaço como uma rede de apoio fundamental no processo migratório autónomo e independente.

Com a incorporação das mulheres no espaço público de produção das "fornadjas", uma nova identidade feminina emergiu na Ribeira de Principal, ou seja, a identidade de mulheres "fornadjeras": mulheres trabalhadoras e provedoras dos respectivos agregados familiares. A emigração permitiu, ainda, a fluidez nas relações de poder, uma vez que as mulheres passaram a ter maiores iniciativas e tomadas de decisões - mesmo que, por vezes, sejam predominantemente relacionadas ao seu espaço de pertença e de intervenção.

\section{Referências}

ARQUIVO HISTÓRICO NACIONAL (AHN). Descoberta das ilhas de Cabo Verde. Praia: Edição AHN, 1998.

ASSIS, Gláucia de Oliveira. "Mulheres migrantes no passado e no presente: gênero, redes sociais e migração internacional". Revista Estudos Feministas, v. 15, n. 3, p. 745-772, Set./Dez. 2007.

BURGESS, Robert G. A pesquisa de terreno. Uma introdução. Oeiras: Celta Editora, 2001.

CARDOSO, Carla Santos de Carvalho. Fornadjeras da Ribeira de Principal. Poder, resistência e identidade feminina no espaço de produção. 2009. Dissertação (Mestrado em Ciências Sociais) - Programa de Pós-Graduação em Ciências Sociais. Universidade de Cabo Verde, Praia.

CARREIRA, António. Cabo Verde. Classes sociais, estrutura familiar, migrações, Lisboa: Ulmeiro, 1972.

CARVALHO, Carla. "Fornadja, campo e casa-espaços em transformação: o caso da Ribeiro de Principal". In: LUCAS, Maria Elizabeth; SILVA, Sergio Baptista da (Orgs.). Ensaios etnográficos na ilha de Santiago de Cabo Verde. Processos identitários na contemporaneidade. Praia: Edições Uni-CV, Porto Alegre: Editora UFRGS, 2009, p. 141-141.

COUTO, Carlos Ferreira. Estratégias familiares de subsistências rurais em Santiago de Cabo Verde. Lisboa: ICP, 2001.

ELLIS, Frank. Rural livelihoods and diversity in developing countries. Oxford: Oxford University Press, 2000.

FURTADO, Cláudio. A Transformação das estruturas agrárias numa sociedade em mudança - Santiago, Cabo Verde. Praia: Instituto Cabo-verdiano do Livro e do Disco, 1997.

GIUFFRÈ, Martina. "Mulheres que ficam e mulheres que migram: dinâmicas duma relação complexa na ilha de Santo Antão (Cabo Verde)". In: GRASSI, Marzia; ÉVORA, lolanda (Orgs.). Género e migrações cabo-verdianas. Lisboa: Imprensa de Ciências Sociais, 2007, p. 193-215.

GHIGLIONE, Rodolphe; MATALON, Benjamin. O inquérito. Teoria e prática. Oeiras: Celta Editora, 2001. 
GRASSI, Marzia. "Cabo Verde pelo mundo: o género na diáspora cabo-verdiana". In: GRASSI, Marzia; ÉVORA, lolanda (Orgs.). Género e migrações cabo-verdianas. Lisboa: Imprensa de Ciências Sociais, 2007, p. 23-63.

GRASSI, Marzia; ÉVORA, lolanda (Orgs.). Género e migrações cabo-verdianas. Lisboa: Imprensa de Ciências Sociais, 2007.

INSTITUTO NACIONAL DE ESTATÍSTICA. Censo 2010. Praia: INE, 2010. Disponível em: http:// www.ine.cv/censo/censo2010.aspx. Acesso em: 07/01/2016.

LEÓN, Magdalena. "El empoderamiento de las mujeres: encuentro del primer y tercer mundos en los estudios de género". La ventana, v. 13, p. 94-106, 2001.

LOBO, Andréa de Souza. "Tão longe e tão perto. Emigração feminina e organização familiar: Boa Vista - Cabo Verde". In: GRASSI, Marzia; ÉVORA, lolanda (Orgs.). Género e migrações cabo-verdianas. Lisboa: Imprensa de Ciências Sociais, 2007, p. 169-191.

MAY, Tim. Pesquisa social: questões, métodos e processos. Porto Alegre: Artmed, 2004.

MINISTÉRIO DO AMBIENTE E AGRICULTURA. Recenseamento geral da agricultura - dados gerais. [Base de dados]. Praia: Direção Geral de Planeamento, Orçamento e Gestão, Direção de Estatística e Gestão de Informação, 2004.

MONTANO, Carlos. Terceiro setor e questão social; crítica ao padrão emergente de intervenção social. São Paulo: Cortez, 2002.

ORTNER, Sherry B. "Poder e projetos. Reflexões sobre a agência". In: GROSSI, Miriam Pillar; ECKERT, Cornelia; FRY, Peter Henry (Orgs.). Conferências e diálogos: saberes e práticas antropológicas. 25a Reunião Brasileira de Antropologia, Goiânia: Nova Letra, 2007, p. 45-80.

ROCHA-TRINDADE, Maria Beatriz. Sociologia das migrações. Lisboa: Universidade Aberta, 1995.

RODRIGUES, Isabel P. B. Fêo. "As mães e os seus filhos dentro da plasticidade parental: reconsiderando o patriarcado na teoria e na prática". In: GRASSI, Marzia; ÉVORA, Iolanda (Orgs.). Género e migrações cabo-verdianas. Lisboa: Imprensa de Ciências Sociais, 2007, p. 123-146.

SILVA, Pedro. Etnografia e educação. Reflexões a propósito de uma pesquisa sociológica. Leiria: Profedições, 2003.

TILLY, Charles. "Transplanted networks". In: YANS-McLAUGHLIN, Virginia (Ed.). Immigration reconsidered. Oxford: Oxford University Press, 1990, p. 79-95.

[Recebido em 16/05/2016

e aceito para publicação em 18/05/2016]

Women at "Fornadja". Weaving (Im)Possible Paths for Emigration

Abstract: The male transnational emigration is an old phenomenon in Cape Verde. Nowadays, in small rural communities, changes regarding activities and social position of the remaining women concerning the occupation of the traditionally male spaces can be observed. Women are occupying that space to provide for their households, as well as a strategy to achieve the paths of emigration. This article analyzes the social and family changes in gender relations that occur simultaneously in the areas of production and domestic spaces in Ribeira de Principal, Santiago Island, Cape Verde, in the context of emigration strategies to Europe.

Keywords: "Fornadja"; Gender; Emigration; Rural Areas, Cape Verde. 